\title{
Analysis of failure of Brakes due to leakages of cylinder through CFD
}

\author{
Shivshankar S. Trivedi ${ }^{1}$, Prashant N. Ulhe ${ }^{2}$ \\ ${ }^{1,2}$ (Mechanical Engg. Department, SSBT's COET, Bambhori, Jalgaon / North Maharashtra University, India)
}

\begin{abstract}
Today's world is very fast moving and in this world we all are well understand that the how important brake is? Effectiveness of braking system are essentials part to avoid accidents and save life. Also majority of accidents in vehicles are happen due to chassis failure and braking failure. Here I take the subject to understand the causes of failure of hydraulic brake systems in SUV. The brakes are the most important active safety of a car and one of its key pieces. However, many drivers do not seem to understand it well. According to a statistics, about $40 \%$ of the defects detected by the ITV correspond to the brakes. It is not enough to bring the car to the shop when something goes wrong.

Leakage is major problem in TMC. In any case if tmc leak it may leads to accident. So leakage and performance of tmc is most important. Various parts of tmc such as piston, spring does not leak. The body of tmc may leak as well seals used in assembly of piston.

In this project the different reasons of leakages are finding and simulation with CFD are carried out.
\end{abstract}

Keywords: Leakage analysis of brake, Body leak analysis , CFD.

\subsection{Background:}

\section{INTRODUCTION}

In automotive engineering, Leakages in brake system cause major/ minor accident to the vehicle Hence it is important to develop the system while assembly to avoid the leakages in brakes accessories like Wheel cylinder, TMC. The tandem master cylinder is a control device that converts non-hydraulic pressure (commonly from a driver's foot) into hydraulic pressure. Leakages are occurs due to contamination of foreign particles in the area of seal moving surface in TMC bore, scratch mark in TMC, Seal Cracks, Body leak due to blow holes or inclusion. Due to this pressure development is minimise causes to distance require to stop the vehicle is increased and failure of brakes may lead to customer complaint from where it is manufactured.

\subsection{Objectives Of The Study: \\ 1.2.1 General Objective:}

The objective of the Analysis is to produce results which may help to rectify problems associated with the Leakages of tendom master cylinder or wheel cylinder because of various reasons to avoid failure of brake system and improve the productivity with minimizing the cycle time. This also help to improve the customer confidence. This analys is carried out on body leak testing unit in a company by changing the testing parameters and analyse with software like CFD \& validate on Test rid. Another objective of this project is to increase the productivity during assembly of Component

\subsubsection{Specific Objectives:}

I. To develop mathematical and Meshing model of the TMC used in brake assembly.

II. Based on the analysis, identify parameters and sections which are highly prone to leak

III.Reduce the cycle time to improve the output of line.

Iv.Arrive at conclusions and propose recommendations.

1.3 METHODOLOGY: To fulfill the objectives of the study the following are used.

I. Literature Review: Survey of books, journal articles, proceedings of international Conferences, manufacturer catalogues, and other relevant literatures are done.

II. Data Collection: Data regarding the leakages parameters in and the SUV segment

III. Modeling and Analysis: The mathematical analysis of leakage of different pressure and time Validation of found mathematical result on the test rig with the same pressure

IV. Conclusions and Recommendations.

\subsection{Organization Of The Thesis:}

The body of this thesis is divided into eight main chapters. The first chapter discusses background and objectives of the study.In addition to this basic introduction of brakes component is given . The second chapter 
covers the review of some of the journal articles, proceedings and publications which were referred during the course of the thesis. Also, as this is very special work there are very less work in this area of thesis will be stated. The mathematical and CFD element modeling is discussed in the sixth chapter. Also, covered in this chapter is meshing of the solid model of the TMC used for the analysis and validation and the mathematical formulation of these elements. The results obtained from the analytical formulation analysis of the TMC and discussions based on these results are included in the eighth chapter. Finally, the eighth chapter covers conclusions drawn based on the results of the analysis and recommendations for future work.

\section{LITERATURE REVEIW}

There are many reasons for the failure of brake system, Leakages are one of them. Although the brake system are using the tendam master cylinder with dual chamber effectiveness of braking will affect due to leakages. A major problem to the brake system is a brake fluid leak, if there is a slow leak in the system it will effect the brake master cylinder by allowing air into the system creating a low peddle and eventual brake operation failure. If a large brake fluid leak is present, fluid escapes, leading to a major brake failure on one half of the system (front or rear).

Running from the brake lines to the brake calipers as well as to the wheel cylinders are rubber brake hoses. It is advised to avoid their exposure to dirt, road grime, salt and other elements. These can make the rubber to become brittle and can produce crack. This will then lead to a failure in the brake system. As well, it is worth noting that brake failure can be caused by water in the brake fluid. When the fluid gets hot, the water will vaporize. This steam can be compressed unlike the water. However, instead of the braking effort being transmitted to the wheels, it is dissipated and the car will fail to brake. So it is important not to forget changing the brake fluid at given interval. (Failure of braking system)

A leak in the brake system, which is a more critical issue than just low brake fluid levels or worn out brake shoes. This article describes several tips in checking for brake fluid leaks. Although a low level of brake fluid does not necessarily signal leakage (as in the case of worn brake shoes), the blinking red warning dash light would probably be the first indicator of leakage. If you are sure that your brake shoes are still okay, but you keep running low on brake fluid, it's time to raise the warning flag. The first thing to do when checking for leaks in the brake system is to locate the leaking point. You can do this by looking for wet spots on the wheels or tires, as well as on the driveway or road where your car is parked. If you do find them, check your brake fluid levels immediately. A puddle underneath the rear of the engine may often signal leakage in or near the master cylinder.( www.brakeproducts.com)

These are the reasons why the leakages in fields and in company leakages are observed because of contamination and casting defects or seal cut on these topics very less research are conducted Here I am working to find out what happens on system if there is defect in TMC casting or what happens when there is contamination?. Why the defect escape from testing.

With help of this research I am simulating the leakage with the help of CFD software and the results are compared with the air as fluid medium and also brake fluid as a medium.

\section{Industrial Methodology}

There are major failures in any automobile, steering failure and brake failure. Before installation of tmc to brake line it should be tasted for its performance and leakage.

Leakage is major problem in TMC. In any case if tmc leak it may leads to accident. So leakage and performance of tmc is most important.

Various parts of tmc such as piston, spring does not leak. The body of tmc may leak as well seals used in assembly of piston.

In company ( In any TMC manufacturing industry), the tmc leakage is find out in assembly section where assembly and all quality test held simultaneously. To test the tmc, is done after every assembled part. Initially empty body is tested by filling fluid with moderate pressure in it. After filling of air pressure it is withhold for 6 seconds, if there will any leakage in body pressure of air will decrease and in case it follows below pre set pressure the body will be rejected for leakage failure. The same test carried for every seal assembly on each station. Small crack developed in seal may leak the tmc.

There are two ways of tasting of leakages,

- Body Leak

Body leak is detected without assemble of any component. As body is made up of casting leak is detected due improper casting. Body leak is detected with charging of 5 bar pressure air inside cylinder bore and leak is detected.

- Seal Leak

Sometimes seal may be assembled reversed due to operator mistake, sometimes small crack in seal or due to contamination of burr present in seal while manufacturing it. Seal leak is detected by vacuum 
pressure of $200 \mathrm{~Pa}$. A vacuum is generated inside cylinder bore when it is assembled ( by piston and piston seal)

\section{Computational Fluid Dynamics}

CFD provides numerical approximation to the equations that govern fluid motion. Application of the CFD to analyze a fluid problem requires the following steps. First, the mathematical equations describing the fluid flow are written. These are usually a set of partial differential equations. These equations are then discretized to produce a numerical analogue of the equations. The domain is then divided into small grids or elements. Finally, the initial conditions and the boundary conditions of the specific problem are used to solve these equations. The solution method can be direct or iterative. In addition, certain control parameters are used to control the convergence, stability, and accuracy of the method.

\section{Mathematical Formulation}

Governing equations

The equations governing the fluid motion are the three fundamental principles of mass, momentum, and energy conservation.

$$
\begin{array}{ll}
\text { Continuity } & \frac{\partial \rho}{\partial t}+\nabla \cdot(\rho \mathrm{V})=0 \\
\text { Momentum } & \rho \frac{D \mathrm{~V}}{D t}=\nabla \cdot \boldsymbol{\tau}_{\mathrm{ij}}-\nabla p+\rho \mathbf{F} \\
\text { Energy } & \rho \frac{D \mathrm{e}}{D t}+p(\nabla \cdot \mathbf{V})=\frac{\partial Q}{\partial t}-\nabla \cdot \mathbf{q}+\mathbf{\Phi}
\end{array}
$$

Where as, $\rho$ is the fluid density, $\mathrm{V}$ is the fluid velocity vector, $\boldsymbol{\tau}_{\mathbf{i j}}$ is the viscous stress tensor, $\mathrm{p}$ is pressure, $\mathrm{F}$ is the body forces, $\mathrm{e}$ is the internal energy, $\mathrm{Q}$ is the heat source term, $\mathrm{t}$ is time, $\Phi$ is the dissipation term, $\mathrm{q}$ is the heat loss by conduction.

Fourier's law for heat transfer by conduction can be used to describe $\mathrm{q}$ as: where $\mathrm{k}$ is the coefficient of thermal conductivity, and $\mathrm{T}$ is the temperature. Depending on the nature of physics governing the fluid motion one or more terms might be negligible.

For example, if the fluid is incompressible and the coefficient of viscosity of the fluid, $\mu$, as well as, coefficient of thermal conductivity is constant, the continuity, momentum, and energy equations reduced.

\subsection{SOFTWARE FOR CFD}

GAMBIT and FLUENT are tools to analysis the fluid flow problems and the branch of science for this problem is known as Computation Fluid Dynamics (CFD)

\section{Mathematical modeling \& Calculations of problem:}

When small crack will develop in TANDEM MASTER CYLINDER body or seal, it will act as a nozzle( converging- diverging nozzle ).

For body or seal leakage

Internal cylinder of body will act as inlet while surrounding or other side of cylinder will act as outlet. While, crack will act as throat of nozzle or orifice.

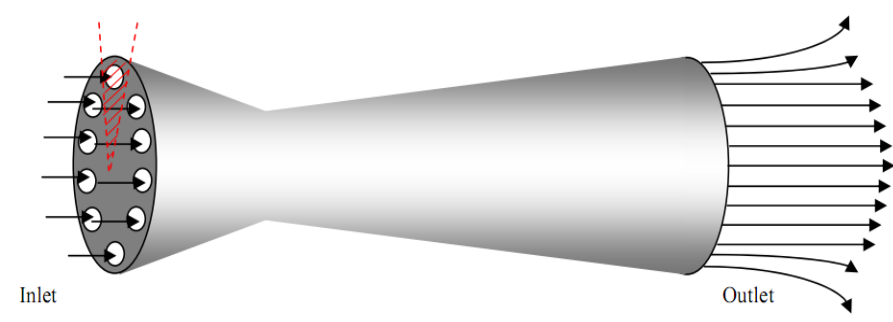

Mathematical model 
Mathematical model of crack consist of mass, momentum and energy conservation equations. When we assume a fixed in space volume of cylinder bore $\Omega$, bounded by close surface $\mathrm{S}$, the mass conservation equation in general form is as the following

\section{Continuity}

$$
\frac{\partial \rho}{\partial t}+\nabla \cdot(\rho \vee)=0
$$

The momentum conservation equation in general form is as follows:

$\rho \frac{D \mathrm{~V}}{D t}=\nabla \cdot \boldsymbol{\tau}-\nabla p+\rho \mathbf{F}$

where: $\tau$-shear stress tensor, F-vector of external forces, p-pressure.

The energy conservation equation in general form is as follows:

$$
\rho \frac{D \mathrm{e}}{D t}+p(\nabla \cdot \mathbf{V})=\frac{\partial Q}{\partial t}-\nabla \cdot \mathbf{q}+\boldsymbol{\Phi}
$$

$\rho$-the fluid density, $\mathrm{V}$-the fluid velocity vector, $\tau$-is the viscous stress tensor, $\mathrm{p}$-pressure, $\mathrm{F}$-the body forces, $\mathrm{e}$ is the internal energy, $\mathrm{Q}$-the heat source term, $\mathrm{t}$ - time, $\Phi$-the dissipation term, $\mathrm{q}$ - the heat loss

\section{Material}

AC2A ( Aluminum alloy)

Tandem master cylinder used in Maruti WagonR, ( YR9)

Dimension of TANDEM MASTER CYLINDER

Bore dia. $=19.06 \mathrm{~mm}$

Depth of TANDEM MASTER CYLINDER $=162.06 \mathrm{~mm}$

Temperature of assembly room $293 \mathrm{~K}$

The maximum air flow through a crack is determined by the critical pressure.

- The critical pressure ratio is the pressure ratio which will accelerate the flow to a velocity equal to the local velocity of sound in the fluid.

Critical flow cracks are also called sonic chokes. By establishing a shock wave the sonic choke establish a fixed flow rate unaffected by the differential pressure, any fluctuations or changes in downstream pressure. A Critical flow crack may provide a simple way to release a gas flow.

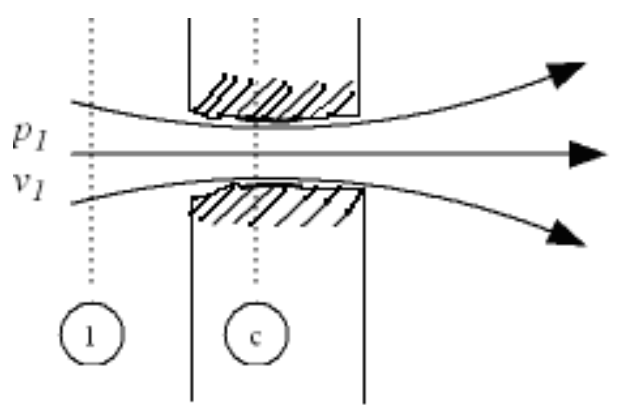

Fig. air leak through TANDEM MASTER CYLINDER body or seal

The ratio between the critical pressure and the initial pressure for a crack can expressed as $\mathrm{pc} / \mathrm{p} 1=(2 /(\mathrm{n}+1)) \mathrm{n} /(\mathrm{n}-1)$

where as,

$\mathrm{pc}=$ critical pressure $(\mathrm{Pa}), \mathrm{p} 1=$ inlet pressure $(\mathrm{Pa})$

$\mathrm{n}=$ index of isentropic expansion or compression - or polytropic constant

For a perfect air undergoing an adiabatic process the index $-\mathrm{n}-$ is the ratio of specific heats $\mathrm{k}=\mathrm{cp} / \mathrm{cv}$. There is no unique value for $\mathrm{n}$. Values for air to used for leak detection,

$$
\text { Air } \mathrm{n}=1.4
$$

The critical pressure ratio for an air crack can be calculated as

$$
\begin{aligned}
\mathrm{pc} / \mathrm{p} 1 & =(2 /(1.4+1)) 1.4 /(1.4-1) \\
& =0.528
\end{aligned}
$$




\section{1) Mass Flow through crack}

The mass flow through a crack with sonic flow where the minimum pressure equals the critical pressure can be expressed as

Seal may be leak or due to foreign inclusion in Tandem master cylinder may cause tear of seal, through which air may be leak. During casting of aluminium alloy, air drop can be trap in cast which may lead porous hole while machining the casting. Cross sectional area of hole may be small.

Hole is circular and dia of hole is $0.2 \mathrm{~mm}$, then

Density of air, $\rho=1.225 \mathrm{~kg} / \mathrm{m} 3$

$$
\begin{aligned}
& \mathrm{A} 2=\pi((0.0002 \mathrm{~m}) / 2) 2 / 2 \\
& \quad=1.57 \times 10-8(\mathrm{~m} 2) \\
& \mathrm{A} 1=\pi((0.019) / 2) 2 \\
& =2.835 \times 10-4(\mathrm{~m} 2)
\end{aligned}
$$

Theoretical flow can be calculated

$\mathrm{q}=\mathrm{A} 2[2(\mathrm{p} 1-\mathrm{p} 2) / \rho(1-(\mathrm{A} 2 / \mathrm{A} 1) 2)] 1 / 2$

where as

$\mathrm{A} 2=$ crack cross sectional area $(\mathrm{m} 2)$

$\mathrm{A} 1=$ cylinder cross sectional area $(\mathrm{m} 2)$

$\rho=$ initial density $(\mathrm{kg} / \mathrm{m} 3)$

For 5 bar pressure testing,

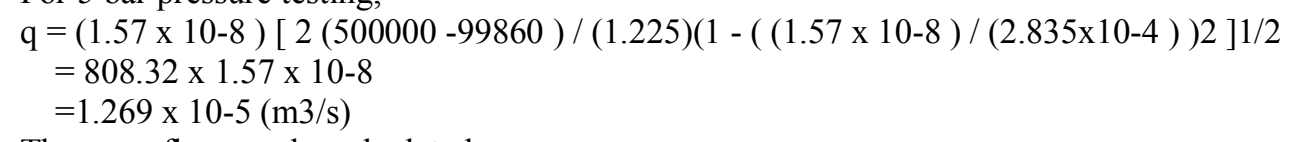

The mass flow can be calculated as:

$\mathrm{m}=\mathrm{q} \rho$

$\mathrm{m}=$ mass flow $(\mathrm{kg} / \mathrm{s})$

$=(1.269 \times 10-5)(1.225)$

$=1.55 \times 10-5 \quad(\mathrm{~kg} / \mathrm{s})$

For $4 \mathrm{sec}$,

As testing time for detection of the leak is minimum 5 seconds, therefore calculating for different time,

$=1.55 \times 10-5 \times 4$

$=6.2 \times 10-5(\mathrm{~kg})$

For $4.5 \mathrm{sec}$,

$=1.55 \times 10-5 \times 4.5$

$=6.975 \times 10-5(\mathrm{~kg})$

For $5 \mathrm{sec}$,

$=1.55 \times 10-5 \times 5$

$=7.75 \times 10-5(\mathrm{~kg})$

Total mass of air in cylinder at 5 bar pressure,

$$
\begin{aligned}
& =(\rho 1 \times \vee \times 5) \\
& =1.225 \times 2.835 \times 0.081 \times 10-4 \times 5 \\
& =1.406 \times 10-4(\mathrm{~kg})
\end{aligned}
$$

Total mass of air in cylinder at 4.5 bar pressure,

$$
\begin{aligned}
& =(\rho 1 \times \vee \times 4.5) \\
& =1.225 \times 2.835 \times 0.081 \times 10-4 \times 4.5 \\
& =1.266 \times 10-4(\mathrm{~kg})
\end{aligned}
$$

Total mass of air in cylinder at 4 bar pressure,

$$
\begin{aligned}
& =(\rho 1 \times \vee \times 4) \\
& =1.225 \times 2.835 \times 0.081 \times 10-4 \times 4 \\
& =1.125 \times 10-4(\mathrm{~kg})
\end{aligned}
$$

So remaining pressure in cylinder is approximately 3.25 bar to 3.5 bar.

Total fall of pressure is 1.5 bar and is not sufficient to detect leak in seal or body of TANDEM MASTER CYLINDER when leak crack will be very small.

For detection of leak allowable pressure limit is 4.5 bar to 5.5 bar. If pressure falls below 4.5 bar then testing machine rejects the component for leakage. And time of leak detection is 5 seconds. If leak is not detected in 5 seconds then Tandem master cylinder is considered as ok. But it may lead serious problem in future of Tandem master cylinder. During continue use of Tandem master cylinder, after some days size of crack increases which causes leak and may lead accident of vehicle. And leak can be detected in minimum 2.5 seconds ( with one second of allowance as considering frictional loss and depth of length of hole).

Now, minimum leakage time is 3.5 seconds filled with 5 bar. 
For 10 bar pressure testing,

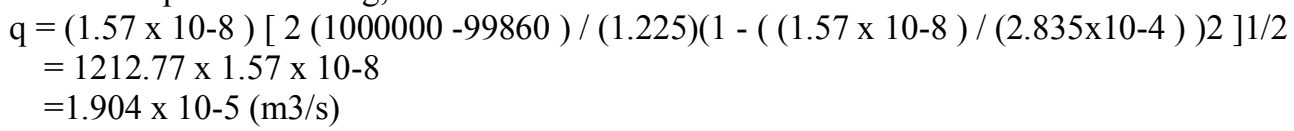

The mass flow can be calculated as:

$\mathrm{m}=\mathrm{q} \rho$

$\mathrm{m}=$ mass flow $(\mathrm{kg} / \mathrm{s})$

$=(1.904 \times 10-5)(1.225)$

$=2.332 \times 10-5 \quad(\mathrm{~kg} / \mathrm{s})$

For $2.5 \mathrm{sec}$,

As testing time for detection of the leak is minimum 5 seconds, therefore calculating for different time,

$=2.332 \times 10-5 \times 2.5$

$=5.83 \times 10-5(\mathrm{~kg})$

For $4.5 \mathrm{sec}$,

$=2.332 \times 10-5 \times 4.5$

$=1.049 \mathrm{x} 10-4(\mathrm{~kg})$

For $5 \mathrm{sec}$,

$=2.332 \times 10-5 \times 5$

$=1.166 \times 10-4(\mathrm{~kg})$

Total mass of air in cylinder at 10 bar pressure,

$$
\begin{aligned}
& =(\rho 1 \times \mathrm{v} \times 10) \\
& =1.225 \times 2.835 \times 0.081 \times 10-4 \times 10 \\
& =2.81 \times 10-4(\mathrm{~kg})
\end{aligned}
$$

Total mass of air in cylinder at 9.5 bar pressure,

$$
\begin{aligned}
& =(\rho 1 \times \mathrm{v} \times 9.5) \\
& =1.225 \times 2.835 \times 0.081 \times 10-4 \times 9.5 \\
& =2.67 \times 10-4(\mathrm{~kg})
\end{aligned}
$$

Total mass of air in cylinder at 9 bar pressure,

$$
\begin{aligned}
& =(\rho 1 \times \vee \times 9) \\
& =1.225 \times 2.835 \times 0.081 \times 10-4 \times 9 \\
& =2.53 \times 10-4(\mathrm{~kg})
\end{aligned}
$$

At 2.5 seconds amount of mass leaked is approximately $5.83 \times 10-5 \quad(\mathrm{~kg})$.

Hence remaining mass is calculated as,

Total mass of cylinder at 5 bar - mass leak after 2.5 seconds

$=2.81 \times 10-4-5.83 \times 10-5=2.227 \times 10-4$

Remaining pressure in cylinder is now 8 bar after 2.5 seconds.

Total fall of pressure is 2 bar and sufficient to detect leak in seal or body of TANDEM MASTER CYLINDER. Even though when crack will be very small, then also fall in pressure will still sufficient to find out leak of TANDEM MASTER CYLINDER.

For detection of leak allowable pressure limit can be change as 9 bar to 11 bar. Time of leak detection is 4 seconds. If leak will not detected in 4 seconds then Tandem master cylinder is considered as ok. Due to higher pressure, leak detection accuracy can increase more and within a short period of time. Due to high pressure even very small leak can be detected easily an in less time. That will increase in production and even that will assured safety of vehicles. Leak can be detected in minimum 2.5 seconds (with one second of allowance as considering frictional loss and depth of length of hole).

Now, minimum leakage time is 3.5 seconds filled with 10 bar.

\section{Software Simulation For Cfd}

GAMBIT and FLUENT are tools for analysis the fluid flow problems and the branch of science of fluidbis known as Computation Fluid Dynamics (CFD)

\section{Gambit:}

GAMBIT full form is Geometry And Mesh Building Intelligent Tool

GAMBIT is used for pre-processing operation (which is required before starting of solution) of fluid flow problem which includes following operations:

- Geometry creation (specifies the domain of fluid flow problem)

- Mesh generation (discretization of domain to solve governing equations at each cell)

- Specifying the boundary zones (name \& type) to apply boundary conditions for problem. 
- $\quad$ GAMBIT export the file containing all the data related to pre-processing.

In this geometry bore diameter of cylinder $19.06 \mathrm{~mm}$ is drawn and $4 \mathrm{~mm}$ thick seal is placed at $81 \mathrm{~mm}$ distance from inlet. And semicircular crack is provided on seal of diameter $0.2 \mathrm{~mm}$ on the corner of cylinder for leak.

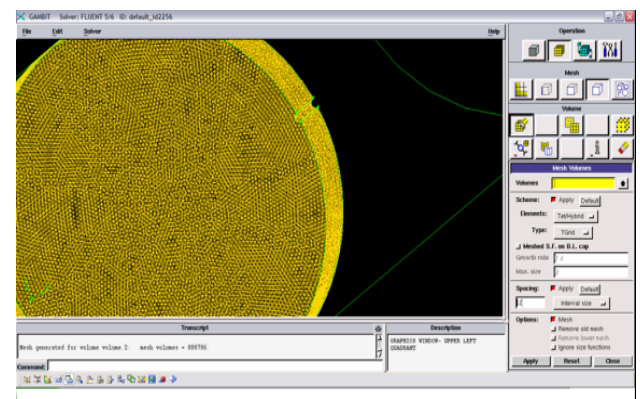

Fig. Meshing of TANDEM MASTER CYLINDER along with seal and leak in GAMBIT

Meshing of cylinder is extremely fine of $0.01 \mathrm{~mm}$ size of element. And selection of element is tetrahedron. Then boundary conditions given as,

1. Pressure inlet

2. Pressure outlet

3. Wall ( for seal and outer surface of body) $\backslash$

4. Fluid zone

Fluent:

This software solve/iterate the problem by importing the file which was exported by GAMBIT to define the problem in FLUENT.

Fluent will require following data to setup the solution for problem.

- Solution method/model

- Material properties

- Boundary and operating conditions for given problem

- Initial conditions and no. of iterations required to converge the solution.

After applying/specifying above data, FLUENT is ready for solution process.

After solution is performed, post processing is done for reviewing the results of solutions to analyze the given problem.

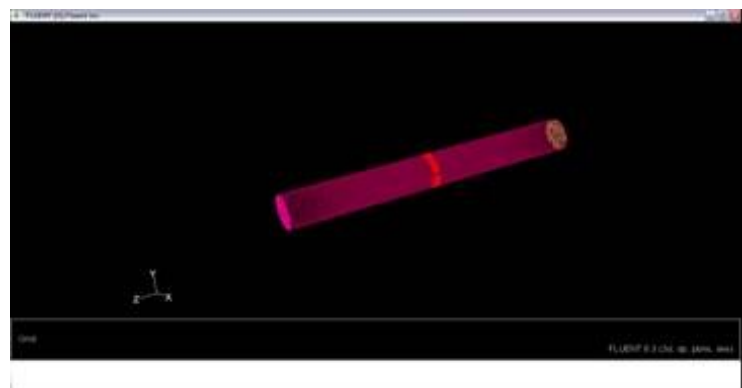

Fig. Grid of TANDEM MASTER CYLINDER along with seal and leak in TANDEM MASTER CYLINDER For 5 bar

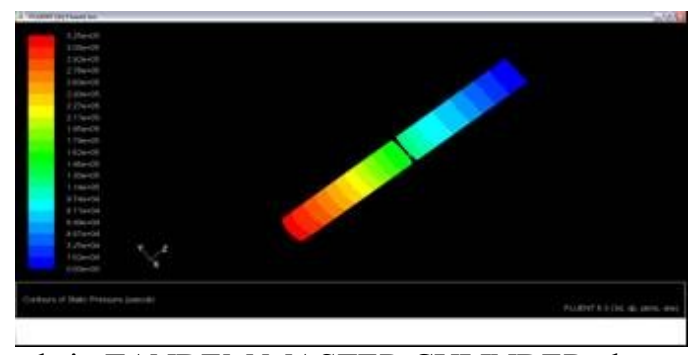

Fig. pressure lost after 2.5 seconds in TANDEM MASTER CYLINDER along with seal and leak in TANDEM MASTER CYLINDER for 5 bar 


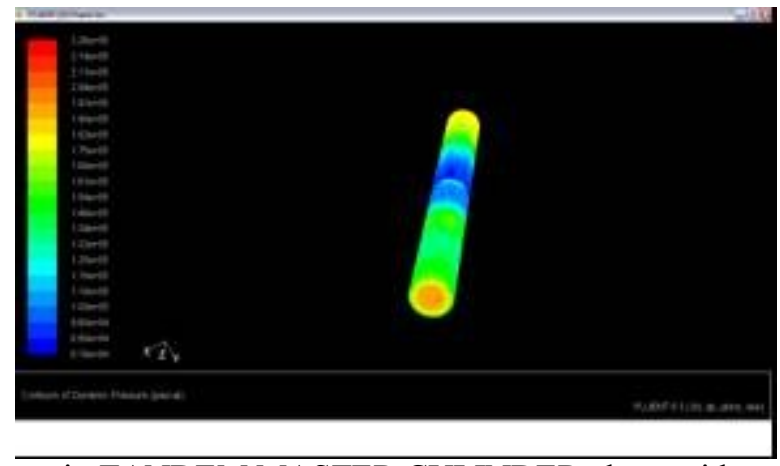

Fig. Dynamic pressure in TANDEM MASTER CYLINDER along with seal and leak for 5 bar For 10 bar

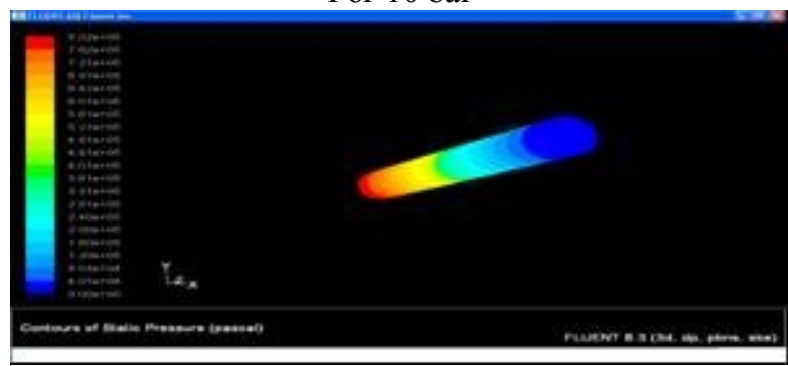

Fig. pressure lost after 2.5 seconds in TANDEM MASTER CYLINDER along with seal and leak in TANDEM MASTER CYLINDER for 10 bar

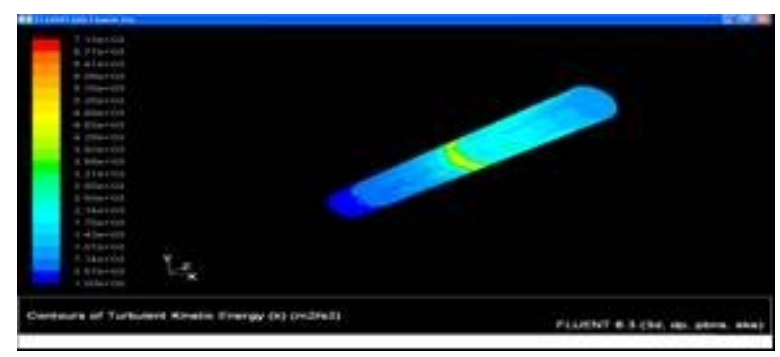

Fig. Distribution of turbulent kinetic energy in TANDEM MASTER CYLINDER along with seal and leak in TANDEM MASTER CYLINDER for $10 \mathrm{bar}$

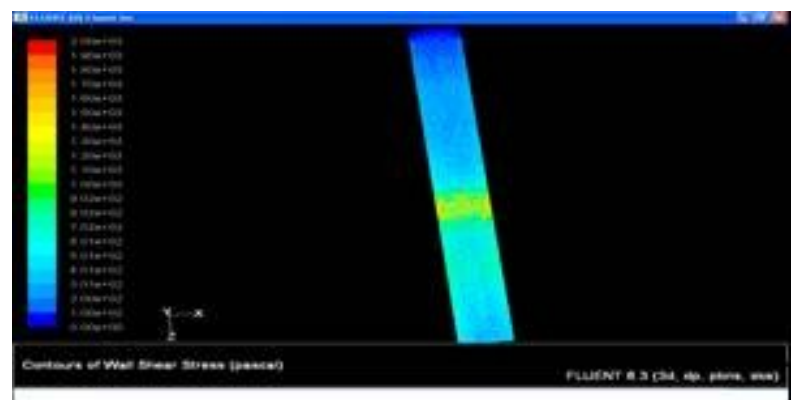

Fig. Max. development of shear stress on seal and leak area in TANDEM MASTER CYLINDER for 10 bar

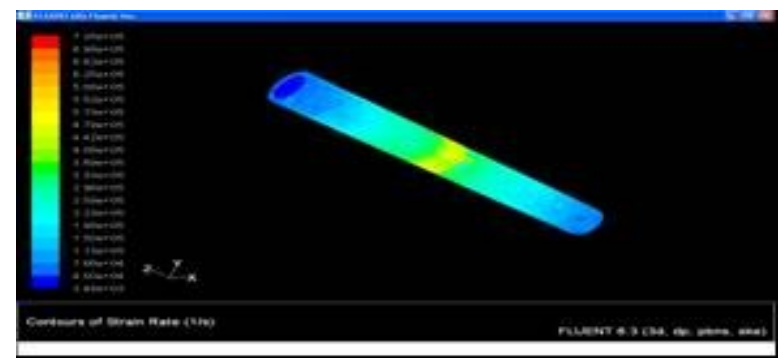

Fig. Maximum development of strain on seal and leak area in TANDEM MASTER CYLINDER for $10 \mathrm{bar}$ 


\section{Validation}

The tandem master cylinder has to pass through many consecutive tests for detection of leak. Before assembling the TANDEM MASTER CYLINDER test for leak detection is body leak. After assembling piston and cylinder the seal detection test is performed at 5 bar pneumatic pressure.

The position of TANDEM MASTER CYLINDER body while leak detection is as,

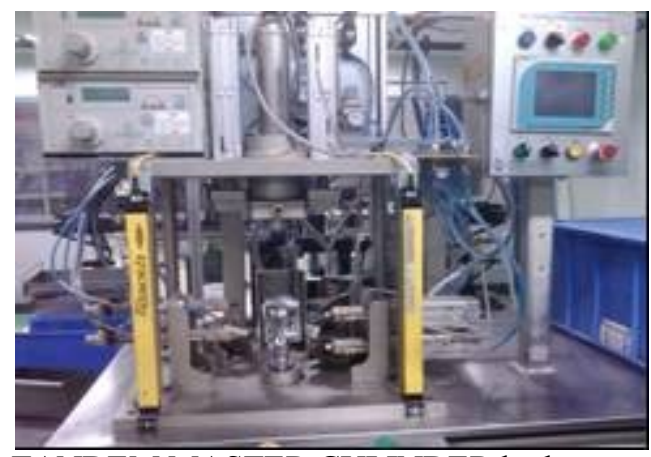

Fig. TANDEM MASTER CYLINDER body tested for leak test.

The leak detector is used to detect leak. Initially pressurized air is charge inside body of TANDEM MASTER CYLINDER and all other ports remains closed by seals as in above figure. The pressure remains in between 4.5 to 5.5 bar. Then leak is detected in 6 seconds. If leak falls below 4.5 bar then job is rejected otherwise it is accepted.

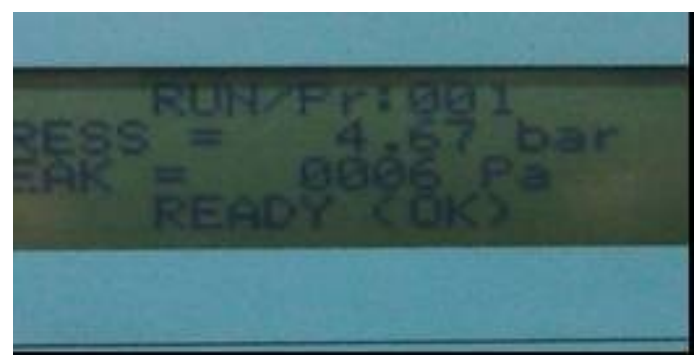

Fig. The body passed leak test as pressure is above 4.5 bar.

For 5 bar pressure testing the failure of TANDEM MASTER CYLINDER body for leak detection is given as,

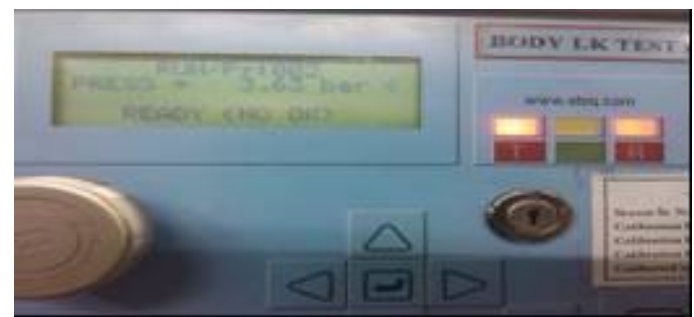

Fig. the body failed in leak test as pressure fall below 4.5 bar.

For 10 bar pressure leak detection, the leak detection limit lies between 9 to 11 bar. If pressure falls below 9 bar, then TANDEM MASTER CYLINDER is failed.

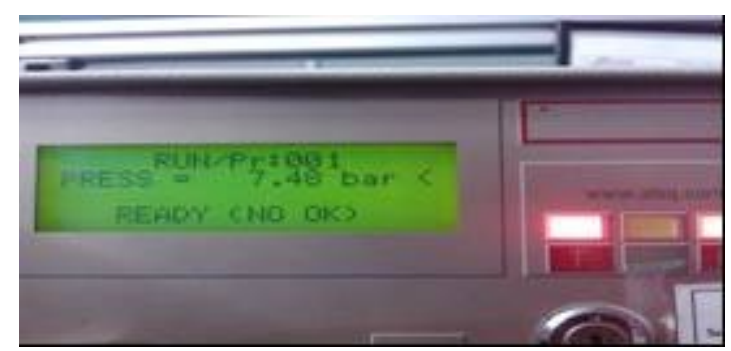




\section{Results}

For leak detection of TANDEM MASTER CYLINDER body at 5 bar and 10 bar pressure the results are as follows,

\begin{tabular}{|l|l|l|l|l|l|}
\hline $\begin{array}{l}\text { Sr } \\
\text { No. }\end{array}$ & Pressure test & $\begin{array}{l}\text { Theoretical pressure } \\
\text { after leak (bar) }\end{array}$ & $\begin{array}{l}\text { Pressure after Leak from } \\
\text { FLUENT (bar) }\end{array}$ & $\begin{array}{l}\text { Experimental pressure after leak } \\
\text { (bar) }\end{array}$ \\
\hline 1 & 5 bar & 3.5 & 3.5 & 3.63 \\
\hline 2 & 10 bar & 8 & 8 & 7.48 \\
\hline
\end{tabular}

Experimental results for number of test for 5 bar and 10 bar pressure test for various leaks in seal, are in following table for 10 different leak bodies.

\begin{tabular}{|l|l|l|l|l|l|}
\hline \multirow{2}{*}{$\begin{array}{l}\text { No. } \\
\text { No. }\end{array}$} & $\begin{array}{l}\text { TANDEM } \\
\text { MASTER } \\
\text { CYLINDER } \\
\text { Body }\end{array}$ & \multicolumn{2}{|l|}{5 bar pressure test } & \multicolumn{2}{l|}{10 bar pressure test } \\
\cline { 3 - 6 } & Pressure after leak & Time & Pressure after leak & Time \\
\hline 1 & 1 & 3.63 & 2.5 & 7.5 & 2.2 \\
\hline 2 & 2 & 4.1 & 2 & 8.1 & 1.6 \\
\hline 3 & 3 & 3.5 & 2.7 & 7.2 & 2.2 \\
\hline 4 & 4 & 3 & 3.3 & 6.3 & 2.8 \\
\hline 5 & 5 & 3.5 & 2.7 & 7.3 & 2.3 \\
\hline 6 & 6 & 2.6 & 3.2 & 6 & 2.8 \\
\hline 7 & 7 & 1.9 & 4.1 & 5.5 & 3.5 \\
\hline 8 & 8 & 2.1 & 3.1 & 5.6 & 2.7 \\
\hline 9 & 9 & 3.8 & 2.7 & 7.9 & 2.1 \\
\hline 10 & 10 & 1.4 & 4.2 & 5.3 & 3.5 \\
\hline
\end{tabular}

\section{Conclusion}

As brake is most critical component in vehicle, its failure may lead accident, so brake lines, TANDEM MASTER CYLINDER and wheel cylinders must function properly. The pressure boost in brake lines is from TANDEM MASTER CYLINDER so it must be work without failure. And it must avoid leakages.

When leak test is performed at 10 bar it increases the production and time requirement for leak detection is low, and even it can detect smallest leakage that can't be possible by using 5 bar pressure leak test. Though 10 bar pressure test adds the installation cost but it can detect maximum errors as well rejection and complaints from customer will be reduced. So, 10 bar pressure leak test is suitable for leak detection of TANDEM MASTER CYLINDER than 5 bar pressure leak test.

In case of company's point of view, customer health are precious than anything hence if the failure are occurs suppliers has to suffer a lot. Debate due to line stoppages or recall of vehicles affects the supplier image and profit also. Hence this types of ideas has to initiate to reduce the complaints.

In case of mass production, output of lines are requires in seconds Hence here to save a second per piece is very cost effective and here is a gain of minimum 2 second per piece helps to increase the output of line.

\section{Acknowledgements}

First of all, I thank God for giving me the strength to accomplish this thesis. I express my sincere thanks with deep sense of gratitude of my Guide Prof. P.N.Ulhe for his encouragement, valuable suggestions, guidance and help throughout the preparation of this project.

I would like to express my deepest appreciation towards Dr.D.S.Deshmukh (H.O.D. Mechanical Engineering Department) whose valuable guidance supported me in preparing the report. I would also like to express my respect and gratitude to Principal of College for providing me this opportunity to prepare the project report.

I take this opportunity to thanks all the professors and staff members of Mechanical Engineering Department who have directly or indirectly helped me for the completion of the project. I am also grateful to other friends of mine who have been very cooperative.

Finally, thanks are due to my mother and father, Dineshkumari and Shrinarayan and my wife, Seema for her support and encouragement

\section{References}

[1]. CFD Analysis Of Air Flow Interactions In Vehicle Platoons By Gokul Krishnan Rajamani School Of Aerospace, Mechanical And Manufacturing Engineering RMIT University August 2006.

[2]. An Introduction To Computational Fluid Dynamics Chapter 20 In Fluid Flow Handbook By Nasser Ashgriz \& Javad Mostaghimi Department Of Mechanical \& Industrial Eng. University Of Toronto Toronto, Ontario.

[3]. A MATHEMATICAL MODEL FOR AIR BRAKE SYSTEMS IN THE PRESENCE OF LEAKS A Thesis By SRIVATSAN RAMARATHNAM Submitted To The Office Of Graduate Studies Of Texas A\&M University In Partial Fulfillment Of The Requirements For The Degree Of MASTER OF SCIENCE August 2008. 
[4]. Brake System Modeling For Simulation And Control By J. Christian Gerdes^ J. Karl Hedric Department Of Mectianical Engineering, University Of California, Berkeiey, CA 94720.

[5]. HYDRAULIC BRAKE SYSTEMS AND COMPONENTS FOR OFF-HIGHWAY VEHICLES AND EQUIPMENT By David E. Keyser Applications Coordinator Keith Hogan OEM Sales MICO, Inc.

[6]. A Text Book On Automobile Chassis And Body Engineering (A Text Book For +2 Vocational And Diploma Students Of Mechanical Engineering) Author Sri. N.R.HEMA KUMAR Lecturer In Vocational,Department Of Vocational Education, Government Junior College, PALAMANER.

[7]. Crack Opening Area Analysis From Circumferential Through Wall Cracks In Pipes By S Rahman, F.W. Brust, N Gladiali A DRY AIR LEAK TEST PRIMER BY QUALITY FIRST SYSTEMS, INC.

[8]. DAVISBURG, MICHIGAN JAMES T. WESTERVELT QUALITY FIRST SYSTEMS, INC. JOE VITALE

[9]. Introduction To Brake Systems - Study Guide @2004 Melior, Inc. 